Preprint

UCRL-JC-137859

\title{
Dislocation Multiplication in the Early Stage of Deformation in Mo Single Crystals
}

\author{
L.M. Hsiung, D.H. Lassila
}

This article was submitted to

MRS Symposium, San Francisco, CA, April 24-28, 2000

\section{March 2, 2000}

U.S. Department of Energy

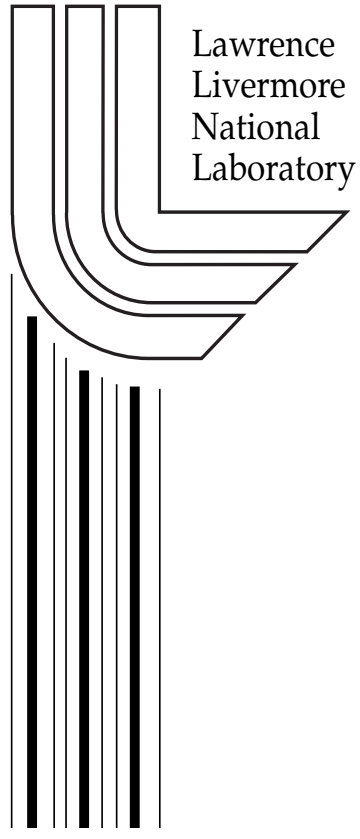




\section{DISCLAIMER}

This document was prepared as an account of work sponsored by an agency of the United States Government. Neither the United States Government nor the University of California nor any of their employees, makes any warranty, express or implied, or assumes any legal liability or responsibility for the accuracy, completeness, or usefulness of any information, apparatus, product, or process disclosed, or represents that its use would not infringe privately owned rights. Reference herein to any specific commercial product, process, or service by trade name, trademark, manufacturer, or otherwise, does not necessarily constitute or imply its endorsement, recommendation, or favoring by the United States Government or the University of California. The views and opinions of authors expressed herein do not necessarily state or reflect those of the United States Government or the University of California, and shall not be used for advertising or product endorsement purposes.

This is a preprint of a paper intended for publication in a journal or proceedings. Since changes may be made before publication, this preprint is made available with the understanding that it will not be cited or reproduced without the permission of the author.

This report has been reproduced

directly from the best available copy.

Available to DOE and DOE contractors from the

Office of Scientific and Technical Information

P.O. Box 62, Oak Ridge, TN 37831

Prices available from (423) 576-8401

http://apollo.osti.gov/bridge/

Available to the public from the

National Technical Information Service

U.S. Department of Commerce

5285 Port Royal Rd.,

Springfield, VA 22161

http://www.ntis.gov/

OR

Lawrence Livermore National Laboratory

Technical Information Department's Digital Library

http://www.llnl.gov/tid/Library.html 


\title{
DISLOCATION MULTIPLICATION IN THE EARLY STAGE OF DEFORMATION IN Mo SINGLE CRYSTALS
}

\author{
L. M. Hsiung and D. H. Lassila \\ Lawrence Livermore National Laboratory, Materials Science and Technology Division, L-369, \\ P.O. Box 808, Livermore, CA 94551-9900, hsiung1@1lnl.gov
}

\begin{abstract}
Initial dislocation structure in annealed high-purity Mo single crystals and deformation substructure in a crystal subjected to $1 \%$ compression have been examined and studied using transmission electron microscopy (TEM) techniques in order to investigate dislocation multiplication mechanisms in the early stage of plastic deformation. The initial dislocation density is in a range of $10^{6} \sim 10^{7} \mathrm{~cm}^{-2}$, and the dislocation structure is found to contain many grown-in superjogs along dislocation lines. The dislocation density increases to a range of $10^{8} \sim 10^{9} \mathrm{~cm}^{-2}$, and the average jog height is also found to increase after compressing for a total strain of $1 \%$. It is proposed that the preexisting jogged screw dislocations can act as (multiple) dislocation multiplication sources when deformed under quasi-static conditions. The jog height can increase by stress-induced jog coalescence, which takes place via the lateral migration (drift) of superjogs driven by unbalanced line-tension partials acting on link segments of unequal lengths. The coalescence of superjogs results in an increase of both link length and jog height. Applied shear stress begins to push each link segment to precede dislocation multiplication when link length and jog height are greater than critical lengths. This "dynamic" dislocation multiplication source is suggested to be crucial for the dislocation multiplication in the early stage of plastic deformation in Mo.
\end{abstract}

\section{INTRODUCTION}

The main purpose of this study is to examine, analyze the initial dislocation structure and deformation substructure of Mo single crystals in order to provide detailed physical mechanisms to facilitate multi-scale modeling and dislocation dynamics simulation [1]. For the success of simulation, it is of paramount importance to have a systematic and rigorous study on dynamic properties of dislocations including dislocation multiplication, motion, and dislocation interaction. Since the initial dislocation structures (dislocation density, dislocation configuration, free dislocation link length, kink and jog density...) can all affect dislocation dynamics during subsequent plastic deformation, the dislocation substructures in as-annealed and quasi-statically compressed Mo crystals were studied and compared. Emphasis has been placed upon the role of initial dislocation structures in dislocation multiplication and motion during early stages of plastic deformation.

\section{EXPERIMENT}

The Mo single crystals used for dislocation dynamics experiment must have low dislocation density in order to analyze the structure with TEM and to subsequently establish initial conditions for simulation. Mo single crystals were obtained from Accumet Materials Company, Ossining, NY. The interstitial impurities (ppm in weight) in Mo are $\mathrm{O}: 25 ; \mathrm{N}:<10 ; \mathrm{H}:<5 ; \mathrm{C}:<10$, respectively. Prior to compression test, the test sample was heat treated at $1500^{\circ} \mathrm{C}$ for $1 \mathrm{~h}, 1200^{\circ} \mathrm{C}$ for $1 \mathrm{~h}$, and $1000^{\circ} \mathrm{C}$ for $1 \mathrm{~h}$ at a vacuum of $8 \times 10^{-11}$ Torr. Testing of single crystals involves compressing the test sample between two platen surfaces under precise conditions. To measure shear strain during compression, a 3-element rosette gage was bonded in the gage section on each side of the sample. The gages were applied with room temperature curing epoxy adhesive. A compression test was performed on a Mo test sample with a [118] compression axis. This orientation was chosen to study single-slip deformation involving the $\left(\mathrm{F}^{2}\right.$ ) [111] slip system. The sample was compressed at a 
nominal strain rate of $10^{-3} \mathrm{~S}^{-1}$. The sample was compressed to a value of approximately $1 \%$ axial strain. TEM foils were sliced from the gage section of the tested piece with the foil sliced parallel to the $(\overline{1} \overline{1} 2)$ plane. TEM specimens were finally prepared by a standard twin-jet electropolishing technique in a solution of 75 vol.\% ethanol and 25 vol.\% sulfuric acid at $\sim 25 \mathrm{~V}$ and $-10^{\circ} \mathrm{C}$.

\section{RESULTS}

\section{Initial dislocation structures in annealed crystals}

The initial dislocation structures in as-annealed Mo examined from [011]-, [01- 1$]-$ and [100]sliced foils are illustrated in a 3D box as shown in Fig. 1. The dislocation density $(\rho)$ is estimated to be on the order of $10^{6} \sim 10^{7} \mathrm{~cm}^{-2}$. Occasionally, cross-grid screw dislocations with Burgers vectors of $\pm_{-}[111]$ and $\pm_{-}\left[1^{\left[{ }^{[}\right.}\right]$were observed in the $\left[0^{[} 1\right]$-sliced foil, which were determined using the $\mathbf{g} \cdot \mathbf{b}$ $=0$ invisible criterion as shown in Fig. 2 . As can be seen clearly that the dislocations of $\mathbf{b}= \pm \ldots$

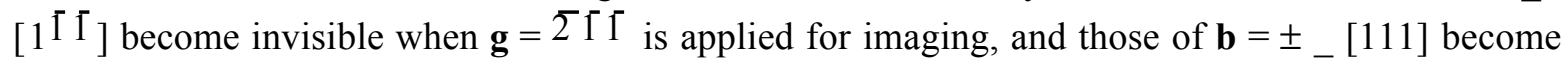
invisible when $\mathbf{g}=2_{2} \Gamma$ is applied for imaging. These dislocation pairs have a near-screw character since their line vectors are nearly parallel to their Burgers vectors. Notice that the appearance of residual contrasts under $\mathbf{g} \cdot \mathbf{b}=0$ conditions suggests that these dislocation lines are not pure screw in character.

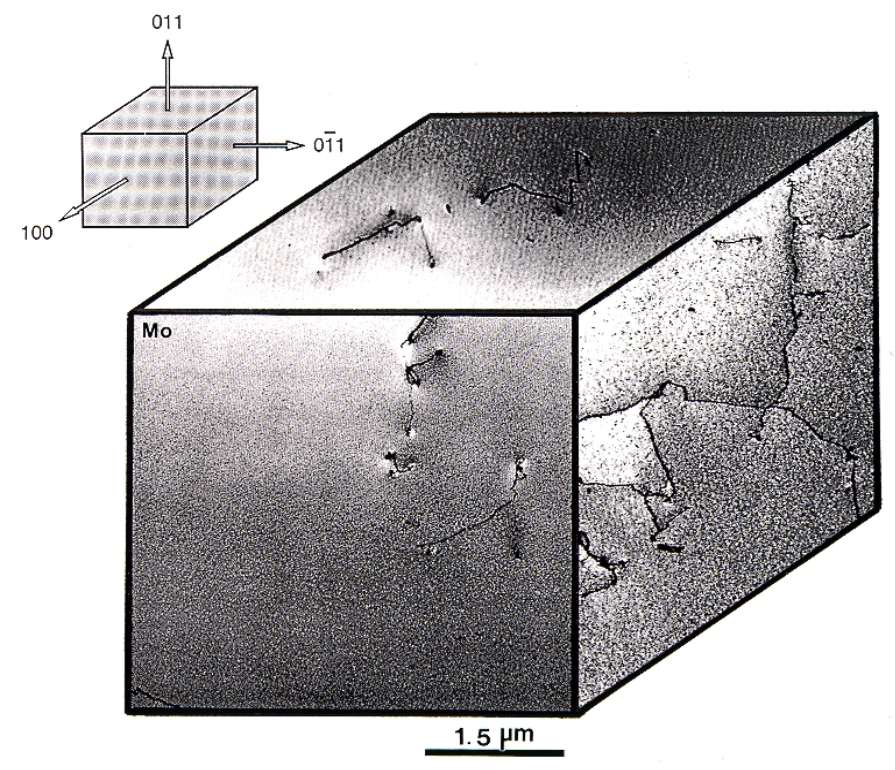

Fig. 1. Initial dislocation structures in as-annealed Mo single crystals.

According to Frank-Read dislocation multiplication mechanism [2], dislocation can multiply by repeatedly bowing out a free segment of dislocation line lying in a slip plane, and the shear stress $(\tau)$ required bowing out a line segment $(l)$ is given as: $\tau \approx \mu b / l$. Thus, there may exist a critical length $\left(l^{*}\right.$ $\left.\approx \mu b / \tau_{a}\right)$ of free segment for a given applied shear stress $\left(\tau_{a}\right)$. Any length of free segment $l$ which is smaller than $l^{*}$ will be permanently immobile, while length of segment greater than $l^{*}$ are potentially mobile. Accordingly, an investigation of the relative density $\left(\rho_{m} / \rho\right)$ of mobile dislocation in slip plane is important for studying the yield strength of crystal. An investigation made on this aspect of dislocation configuration is shown in Fig. 3. Here, an "in-plane" [111] dislocation segment $(\sim 5 \mu \mathrm{m}$ in length) in the $\left\{0^{\mathrm{t}} 1\right\}$ plane is shown. Notice the bend-over at two ends of the segment, which indicates that a dislocation line is not entirely lying in one crystallographic plane. However, there is an uncertainty whether the observed segment is truly a free dislocation segment without any other pinning points such as short jog segments formed on the dislocation line. In other words, there is a 
difficulty to define free segment length by viewing dislocation from this orientation since it is infeasible to locate the pinning points formed by jog segments along the dislocation line.

(a)

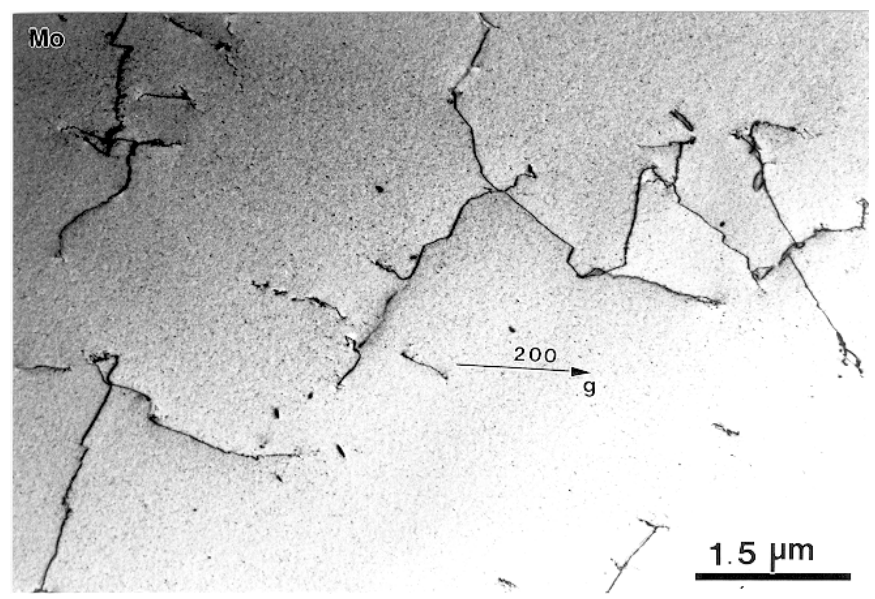

(b)

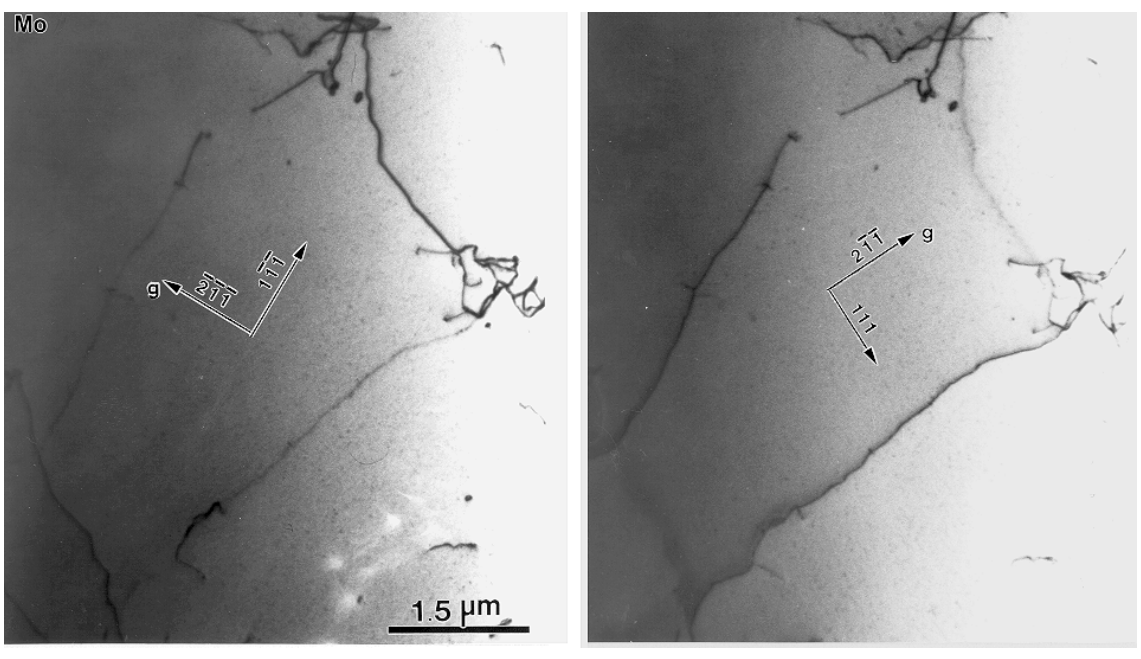

Fig. 2. Bright-field TEM images showing (a) the formation of cross-grid dislocations, and (b) a $\mathbf{g} \cdot \mathbf{b}$ analysis for the character of cross-grid dislocations; (left) $\mathbf{Z}$ (zone axis) $\approx\left[0^{{ }^{-}} 1\right], \mathbf{g}=$ $2 \Gamma \Gamma$, dislocations of $\mathbf{b}= \pm \pm_{-}[111]$ become invisible, and (right) $\mathbf{Z} \approx\left[0^{1^{-}} 1\right], \mathbf{g}=2^{{ }^{-1} 1^{-}}$, dislocations of $\mathbf{b}= \pm \ldots\left[1^{\mathrm{r}}\right]$ become invisible.

In fact, the dislocation segment length viewed from the $\left\{{ }^{\mathrm{T}} 01\right\}$-sliced foils may be a measure of the line waviness along the foil normal. This can be visualized readily from a cross-sectional view of _ $\left[{ }^{1{ }^{\dagger}} 1\right]$ screw dislocation shown in Fig. 4(a), in which the screw dislocation in the (011) plane was observed from the foil sliced parallel to the $\left(0^{F} 1\right)$ plane. Here, the existence of many long superjogs $\left(50 \sim 100 \mathrm{~nm}\right.$ in height) along the $\left[{ }^{[t} 1\right]$ screw dislocation line can be seen. In addition, the dislocation line is found to skew away from the $\left[{ }^{-1} 1\right.$ ] direction revealing that the dislocation line is also associated with many short superjogs [jog height $(\mathrm{d})<1 \mathrm{~nm}$ ] or elementary jogs [jog height $=$ interplanar spacing of $\left({ }^{t_{21}}\right)$ plane $=0.135 \mathrm{~nm}$ ]. Noted that the height of short superjogs or elementary jogs is too short to be resolvable using conventional TEM imaging techniques. This examination suggests that the short dislocation segments appeared in the $\left\{^{t} 01\right\}$-sliced foils is 
attributed to the formation of jogs along a screw dislocation line which causes it to lie across many $\{\overline{1} 01\}$ planes instead of one. Consequently, screw dislocation lines are chopped into short segments

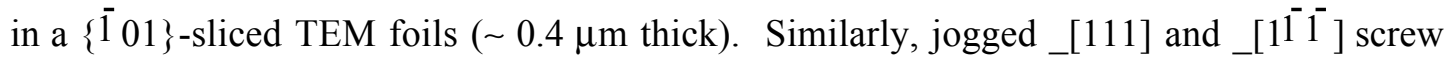

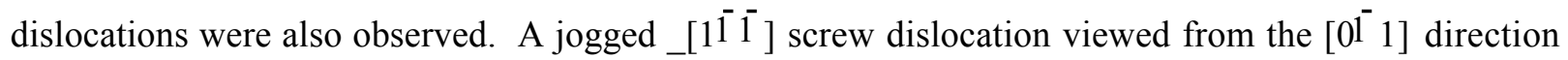
is shown in Fig. 4(b). Here, many large superjogs $(50 \sim 100 \mathrm{~nm}$ in height) can be readily seen along the dislocation line. Also notice that the lengths of each free segment linked between two superjogs are unequal.
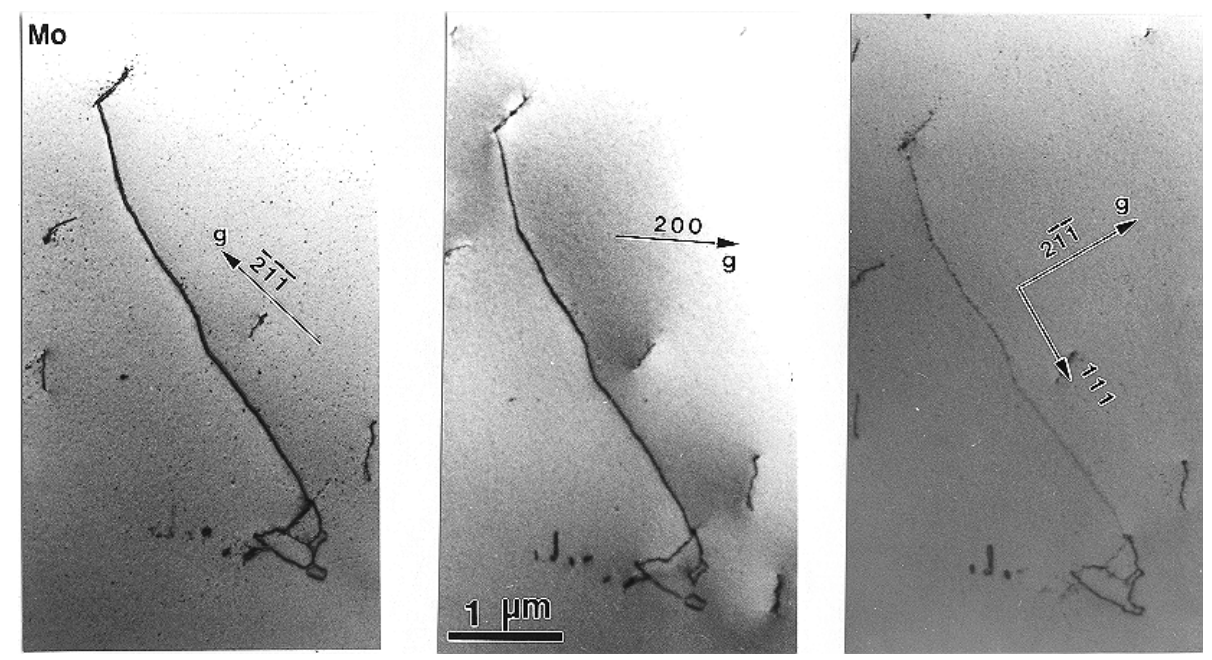

Fig. 3. A $\mathbf{g} \cdot \mathbf{b}$ analysis for $\mathbf{a} \pm_{-}[111]$ screw dislocation formed in $\left(0^{{ }^{-}} 1\right)$-sliced Mo.

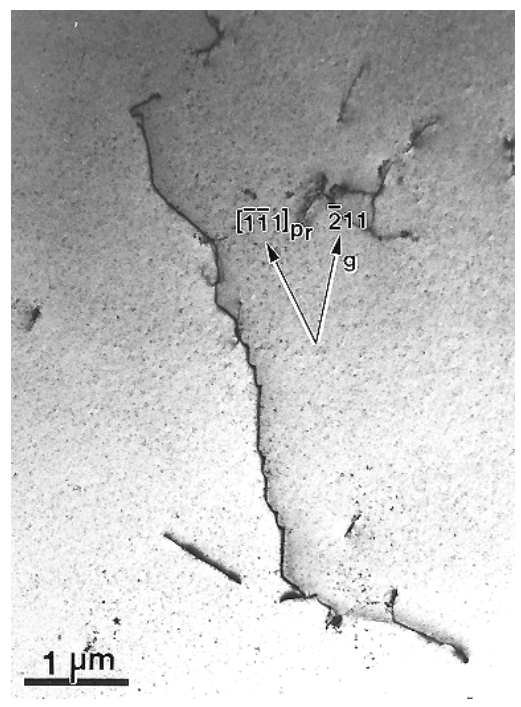

(a)

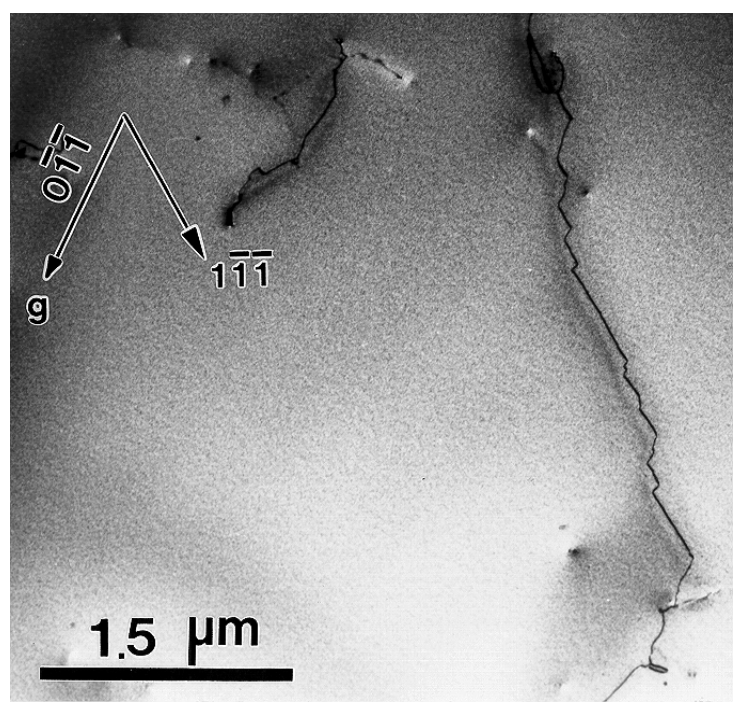

(b)

Fig 4. TEM images showing (a) a jogged _[ $\left.{ }^{\vdash}{ }^{-} 1\right]$ screw dislocation and (b) a jogged $\left[1^{1-1^{-}}\right]$ screw dislocation viewed from the $\left[0^{\mathrm{r}} 1\right]$ direction in as-annealed Mo.

\section{Deformation substructure}


Typical deformation substructures of a crystal compressed for $1 \%$ are shown in Fig. 5. The dislocation density increases about two orders of magnitude to a range of $10^{8} \sim 10^{9} \mathrm{~cm}^{-2}$. Although the _[111] screw dislocations are prevalent, other secondary dislocations are also operative. Notice that many superjogs (marked by arrows) are seen along screw dislocation lines, and the average jog height, and free segment between superjogs are found to increase significantly in comparison with that observed in as-annealed samples (Fig. 4). In addition, the screw dislocation lines become much straighter and longer comparing to those in as-annealed crystals. The increase of cross-grid screw dislocations, as shown in Fig. 5(b), indicates that multiple slip systems have been activated in the early stage of plastic deformation. It is worth noting that few junction dislocations are formed at the cross points of the cross-grid dislocations during the stage.

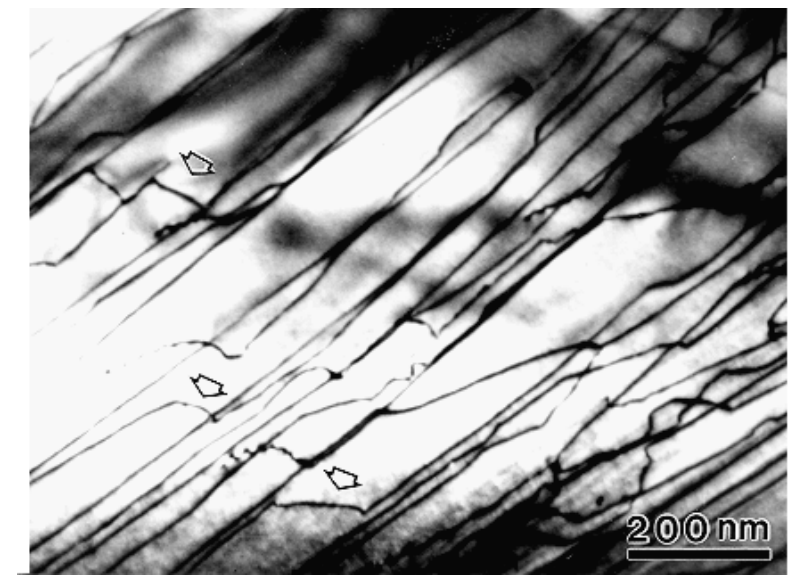

(a)

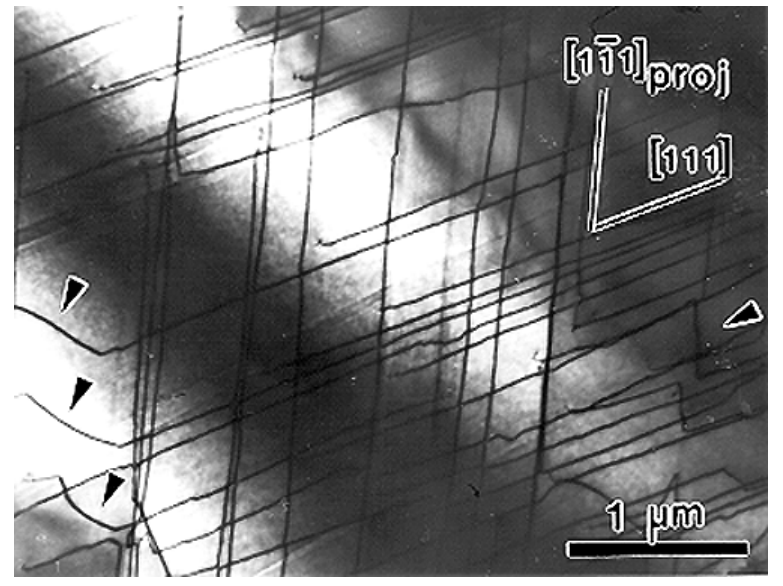

(b)

Fig. 5. Typical dislocation structures observed in a crystal compressed for $1 \%$.

\section{Proposed dislocation multiplication mechanisms}

Based upon the observations shown in Figs. 4 and 5, dislocation multiplication during the early stage of plastic deformation in Mo single crystals can be rationalized by mechanisms proposed and illustrated in Fig. 6. Here, screw dislocation segments pinned by superjogs bow out between the superjogs under an applied shear stress $(\tau)$ to a certain curvature, yet they are immobile since the initial length $\left(l_{o}\right)$ of each free segment is smaller than a critical length $\left(l^{*} \approx \mu b / \tau\right)$ as defined earlier. Beside the force exerted on dislocation segments by the applied shear stress, each superjog is subjected to a net force parallel to the Burgers vector due to unbalanced line-tension partials acting on the segments of line between unevenly spaced jogs. Thus, each jog will move in such a direction so that the shorter segments ( $\mathbf{C D}$ and $\mathbf{E F}$ ) become still shorter and the longer segments $\left(\mathbf{A B}^{\mathbf{B}}\right.$ and GH ) are expanded [3]. The superjogs of like-signs tend to coalescence in order to reduced line energy and resulting in the increase of jog height [4]. Consequently, the stress-induced jog coalescence renders an increase of both segment length and jog height.

Applied shear stress eventually begins to push each line segment between jogs to precede dislocation multiplication when the length of line segments ( ${ }^{\mathbf{J}}$ and $\mathbf{K} \mathbf{L}$ ) and height of superjog $\left(\mathbf{J K}\right.$ ) are greater than critical values, i.e. $l^{*} \approx \mu b / \tau$ and $d_{c} \approx \mu b / 8 \pi(1-v) \tau$. Here, $d_{c}$ can be defined by a mutual attraction force between adjacent bowing edge segments of opposite signs. That is, the originally immobile screw dislocations become multiple sources for dislocation multiplication as a result of the jog coalescence process. This "dynamic" dislocation multiplication source is suggested to be crucial for the dislocation multiplication in the early stage of plastic deformation in Mo. 


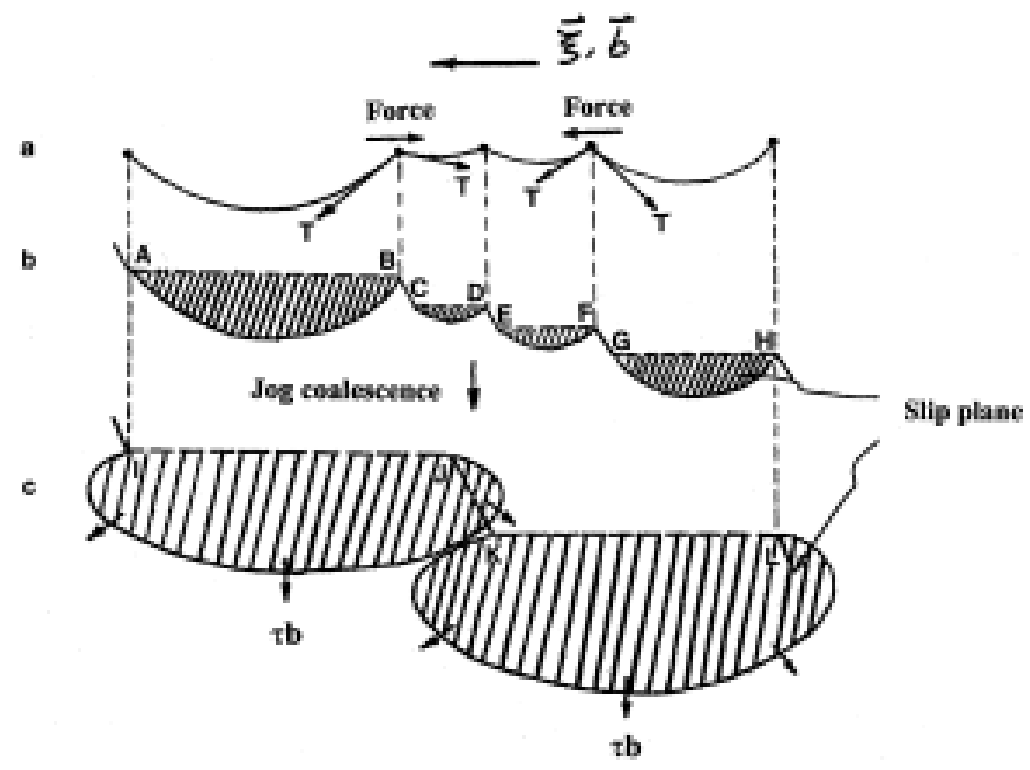

Fig. 6. Schematic illustrations of dislocation multiplication from a jogged screw dislocation. (a) A top view showing dislocation segments pinned by superjogs bowing under stress to a curvature, net forces are generated on jogs due to unbalanced line-tension partials acting on the free segments of unequal lengths. (b) A tilt view of (a) shows the initial heights of likesign superjogs. (c) Both segment length and jog height increase as a result of stress-induced jog coalescence.

\section{CONCLUSIONS}

Screw dislocations in association with grown-in superjog segments were observed within annealed Mo single crystals. It is proposed that the jogged screw dislocations can act as a dynamic multiplication source for dislocation multiplication when deformed at quasi-static conditions as a result of stress-induced migration and coalescence of superjogs. The jog coalescence can take place via the lateral migration (drift) of jog segments driven by unbalanced line tension partials acting on line segments (between jogs) of unequal lengths. The coalescence of jog segments results in the increase of both segment length and jog height. The jog coalescence continues until the segment length and jog height are greater than critical values so that applied stress begins to push each line segment to precede multiple dislocation multiplication.

\section{ACKNOWLEDGEMENTS}

This work is performed under the auspices of the U.S. Department of Energy through contract \# W-7405-Eng-48 with Lawrence Livermore National Laboratory.

\section{REFERENCES}

1. G. H. Campbell et al., Mater. Sci. and Engrg. A251 (1998), p. 1.

2. F. C. Frank and W. T. Read, in "Symposium on Plastic Deformation of Crystalline Solids," Carnegie Institute of Technology, Pittsburgh, 1950, p. 44.

3. J. Weertman and P. Shahinian, Trans. A.I.M.E. 209 (1957), p. 1298.

4. N. Louat and C. A. Johnson, Phil. Mag. 7 (1962), p. 2051. 